INTERNATIONAL HIGHER EDUCATION Number 75 Spring 2014

Pages 5-7

\title{
MOOCs as Neocolonialism: Who Controls Knowledge?
}

\begin{abstract}
PHILIP G. ALTBACH
Philip G. Altbach is research professor and director of the Center for International Higher Education at Boston College. E-mail: altbach@bc.edu.
\end{abstract}

Massive open online courses, or MOOCs, are the latest effort to harness information technology for higher education. The concept takes advantage of the significant advancements in technology that permits much more interactive pedagogy as well as more sophisticated delivery of content. While MOOCs are still in a nascent stage of development, their sponsors as well as many commentators and policymakers are enthusiastic, and see them as an inexpensive and innovative way of delivering content to vast audiences, while others see potential for profits.

One aspect of the MOOC movement has not been fully analyzed-who controls the knowledge. Considering where the content and the technology that support MOOCs originate, the answer is clear. MOOCs are largely an Americanled effort and the majority of the courses available so far come from universities 
in the United States or other Western countries. The main providers are also in the technologically advanced countries. The technology in use was developed in Silicon Valley, Kendall Square in Cambridge, Massachusetts, and other hubs of information technology innovation. Early adopters have a significant advantage in this arena. While globalization has increased the sway of the academic centers in economically powerful countries, MOOCs promise to enhance this higher education hegemony by harnessing technology to the existing knowledge network.

Others, in diverse and less-developed regions of the world, are joining the MOOC bandwagon, but it is likely that they will be using technology, pedagogical ideas, and much of the content developed elsewhere. In this way, the online courses threaten to exacerbate the worldwide influence of Western academe, bolstering its higher education hegemony.

Two of the original MOOC sponsors, Coursera and EdX, are American initiatives - the first founded by Stanford professors and based in Silicon Valley in California and the second established by Harvard University and the Massachusetts Institution of Technology. Many other top universities, mainly in the United States, have joined these efforts. Coursera offers 535 courses in many fields of study -24 percent of the courses originate from outside the United States, Canada, the United Kingdom, and Australia; EdX provides 91 courses- 
19 of which are from outside North America and the United Kingdom. Some of these courses enroll as many as 300,000 students, with average enrollments of approximately 20,000. The large majority of students come from outside the United States. Completion rates seem to be low-most less than 13 percent. Many in the MOOC movement are seeking to earn profits from MOOCs-a goal so far unmet.

\section{Who Controls KNOWLedge AND Why Does It MatTer?}

The large majority of MOOCs are created and taught by professors in the United States. Companies and universities with the funds to develop good MOOC courses-and with high development costs-are American. Udacity, an American MOOC provider, estimates that creating a single course costs $\$ 200,000$, and is increasing to $\$ 400,000$. The University of California, Berkeley, estimates development costs at between $\$ 50,000$ and $\$ 100,000$, with access to sophisticated technology required.

For the most part, MOOC content is based on the American academic experience and pedagogical ideas. By and large, the readings required by most MOOC courses are American or from other Western countries. Many of the courses are in English, and even when lectures and materials are translated into other languages the content largely reflects the original course. The vast majority 
of instructors are American. It is likely that more diversity will develop but the basic content will remain.

Approaches to the curriculum, pedagogy, and the overall philosophy of education differ according to national traditions and practices, and may not reflect the approaches provided by most MOOC instructors or the companies and universities providing MOOC content and pedagogy. No doubt, those developing MOOCs will claim that their methods are best and reflect the most advanced pedagogical thinking. Perhaps, there are a range of approaches to learning and many traditions.

Why is this important? Neither knowledge nor pedagogy are neutral. They reflect the academic traditions, methodological orientations, and teaching philosophies of particular academic systems. Such academic nationalism is especially evident in many social science and humanities fields, but it is not absent in the sciences. While academics who develop MOOC courses are no doubt motivated by a desire to do the best job possible and to cater to a wide audience, they are to a significant extent bound by their own academic orientations.

Since the vast majority of material used comes from Western academic systems, examples used in science courses are likely to come from America or Europe because these countries dominate the literature and articles in influential 
journals, and are taught by well-known professors from high-profile universities. Modes of inquiry reflect the Western mainstream. While this knowledge base and pedagogical orientation no doubt reflect current ideas of good practice, they may not be the only approach to good scientific inquiry or content.

These issues come into even sharper focus in the social sciences and humanities. In fields such as literature and philosophy, most courses reflect Western traditions of knowledge, the Western literature canon, and Western philosophical assumptions. The social sciences reflect Western methodologies and basic assumptions about the essentials of scientific inquiry. Mainstream ideas and methods in fields from anthropology to sociology reflect Western trends, especially the American academic community. The major academic journals, editors, and editorial boards, big academic publishers are located in the global centers of knowledge, like Boston, New York, and London. It is, under these circumstances, natural that the dominant ideas from these centers will dominate academic discourse, and will be reflected in the thinking and orientations of most of those planning and teaching MOOCs. MOOC gatekeepers, such as Coursera, Udacity, and others, will seek to maintain standards as they interpret them, and this will no doubt strengthen the hegemony of Western methodologies and orientations. 
English not only dominates academic scholarship in the 21st century, but also the MOOCs. English is the language of internationally circulated academic journals; researchers in non-English-speaking environments are increasingly using English for their academic writings and communication. Major academic Web sites tend to be in English as well. Because English is the language of scholarly communication, the methodological and intellectual orientations of the English-speaking academic culture hold sway globally.

The implications for developing countries are serious. MOOCs produced in the current centers of research are easy to access and inexpensive for the user, but may inhibit the emergence of a local academic culture, local academic content, and courses tailored specially for national audiences. MOOCs have the potential to reach nonelite audiences, thus extending the influence of the main academic centers.

\section{The NeOCOlONiALISM OF THE WiLling}

Those responsible for creating, designing, and delivering MOOC courses in all fields are in general part of the academic culture of major universities in the English-speaking countries. They do not seek to impose their values or methodologies on others, influence happens organically and without conspiracies. A combination of powerful academic cultures, the location of the 
main creators and disseminators of MOOCs, and the orientation of most of those creating and teaching MOOCs ensures the domination of the largely Englishspeaking academic systems. The millions of students choosing to participate in MOOCs from all over the world do not seem to be concerned about the nature of the knowledge or the philosophy of pedagogy that they are studying. Universities in the middle-income and developing world do not seem concerned about the origins or orientations of the knowledge provided by the MOOCs or the educational philosophies behind MOOC pedagogy.

I do not mean to imply any untoward motives by the MOOC community. I am not arguing that the content or methodologies of most current MOOCs are wrong because they are based on the dominant Western academic approaches. But I do believe it is important to point out that a powerful emerging educational movement, the Massive Open Online Courses, strengthens the currently dominant academic culture, perhaps making it more difficult for alternative voices to be heard. 